\title{
Responsible Innovation in Social Epistemic Systems: The P300 Memory Detection Test and the Legal Trial
}

\author{
By John Danaher* \\ *PhD (UCC), Lecturer in Law, Keele University
}

\begin{abstract}
Memory Detection Tests (MDTs) are a general class of psychophysiological tests that can be used to determine whether someone remembers a particular fact or datum. The P300 MDT is a type of MDT that relies on a presumed correlation between a detectable neural signal (the P300 "brainwave") in a test subject, and the recognition of those facts in the subject's mind. The P300 MDT belongs to a class of brain-based forensic technologies which have proved popular and controversial in recent years. With such tests increasingly being proffered for use in the courtroom - to either support or call into question testimony - it would behoove the legal system to have some systematic framework for ensuring that they are used responsibly. In this paper, I defend one such framework for ensuring that this is the case: the legitimacy enhancing test. According to this test, it is appropriate to make use of technologies such as the P300 MDT whenever doing so would (probably) enhance the legitimacy of the trial. I argue that this test addresses tensions between scientific and legal norms of evidence, and exhibits a number of additional virtues including unification, simplicity and flexibility.
\end{abstract}

\section{Introduction}

The set-up is a familiar one. A nervous suspect, his body wired-up to record his autonomic responses, sits in the chair. An intimidating questioner hovers nearby, a list of questions in her hand. She starts off easy, asking the suspect to state his name and date of birth. But soon things escalate in emotional intensity. She asks awkward questions about his childhood, such as "Did you ever lie to get out of trouble?". Finally, she moves into the core of the interview: "Where were you on the night of the $25^{\text {th }}$ ?", "Did you kill the victim?". 
This scenario, played out on screen in an endless series of police procedurals, describes the essence of the classic polygraph ${ }^{1}$ lie detector test. The test, originally developed by John A. Larson in $1921,{ }^{2}$ is an object of suspicion and cultural obsession. It speaks to our fears and desires. On the one hand, anything that allows us to look past the often biased and distorted nature of testimony, to the real intentions and motivations of the speaker, could be a major boon to the legal system. But on the other hand, anything that looks beneath our public expressions, and into the workings of our minds, seems to threaten our cognitive autonomy, invade our privacy, and erode our sense of trust. Little wonder then that, since the earliest days, the polygraph test has never truly been welcomed by courts of law. ${ }^{3}$ (Note: references to courts of law throughout this paper are to those found in the AngloAmerican legal systems most familiar to the author, specifically: Ireland, England and Wales, and the United States. No claims are made about continental legal systems.)

But that is the past, this paper is concerned with the future. Since 1921 things have changed. New, more sophisticated, versions of the lie-detecter test have arisen, with the latest wave incorporating brain-imaging techniques $;{ }^{4}$ and alternative "mind-reading" tests have been proposed, developed and investigated. ${ }^{5}$ One particular alternative is the P300 memory detection test $\left(\mathrm{MDT}^{6}\right)$, which, instead of detecting deception, locates forensically valuable information in a person's brain. Already used, with minimal success, ${ }^{7}$ in legal trials, there are an increasing number of advocates for the forensic use of this technology. ${ }^{8}$ The question is whether the advocates are right that this technology should be more welcome than its controversial predecessors?

${ }^{1}$ Iacono (2008); National Academies of the Sciences (2003); Furedy, J. (1996); Furedy, J., and Heselgrave, R. (1988); Ben-Shakar, G. (2002)

${ }^{2}$ Adler, K. (2007)

${ }^{3}$ On the early rejection of the lie detector test, see Frye v United States (1923) 293 F. 1013. Schauer, F. (2012)

${ }^{4}$ Schauer (2012) and Schauer, F. (2010

${ }^{5}$ Verscheure, Ben-Shakar and Meijer (2011).

${ }^{6}$ I take the name from Meegan, D. (2008). Roughly equivalent terms are "Guilty Knowledge Test" or "Concealed Information Test", but both of those carry unwelcome pejorative implications (guilt in the first instance and concealment in the second). "Memory Detection" is a more neutral, yet still descriptively appropriate term.

${ }^{7}$ Lawrence Farwell famously started the company Brainwave Science in order to push the forensic use of his "brainfingerprinting" version of the P300 MDT. A full analysis of his attempts can be found in Rosenfeld, J. (2005). A response to this can be found in Farwell, L. (2011)

${ }^{8}$ Verscheure et al (2011) includes several papers that speak in glowing terms about memory detection tests. 
This paper tries to answer that question by defending a novel framework for the responsible use of the P300 MDT. The framework, building on concepts from democratic theory and social epistemology, provides a simple, unifying test for the responsible use of the P300 MDT. This in turn feeds into an analysis of the responsible innovation of any social system that generates judgments of truth and falsity (hereinafter called "social epistemic systems"). ${ }^{9}$ Thus, the paper aims not only to discuss a particular technology, but also to build an evaluative bridge between norms of scientific and technological success, and norms for the successful design of social epistemic systems, such as the legal trial.

The remainder of the paper is structured as follows. In section 2, I briefly outline some of the salient features of the P300 MDT, explaining how it is distinct from the more widely-discussed fMRI lie detector, and highlighting the benefits and risks associated with the technology. In section 3, I analyse some tensions between scientific and legal standards of evidential success, recently highlighted by Frederick Schauer, which can affect our willingness to make use of forensic techniques of this sort, and which are not satisfactorily addressed by existing tests for the admissibility of scientific evidence. In section 4 , I propose and defend a novel framework that tries to resolve these tensions, something I call the LegitimacyEnhancing Test (LET). This gives a roadmap for the responsible use of emerging technologies, and a roadmap for the responsible innovation of the legal trial. Finally, in section 5, I apply this test to the P300 MDT.

\section{The Allure of the P300 MDT}

A memory detection test (MDT) is a test that purports to detect the presence of certain memories in a person's mind. The P300 MDT is simply one instance of such a test. ${ }^{10}$ It relies on electro-encephalographic (EEG) imaging, which is used to record variations in electrical activity across different regions of the brain. ${ }^{11}$ The brain displays constant and sometimes consistent variation in electrical activity (brainwave patterns), with some patterns being associated with certain types of conscious awareness (e.g. delta waves are associated with sleep).

If a discrete stimulus is presented to a subject who is hooked-up to an EEG, a "blip" in the otherwise constantly varying levels of activity can be detected. This is known as an evoked response potential (ERP). The P300 is particular kind of ERP that seems to arise whenever recognised, meaningful and rare stimuli are presented to a test subject. ${ }^{12}$ As a result, the P300 is thought to be an ideal candidate for a MDT. If the testing paradigm is robust enough, and if it is protected from confounding variables, then the detection of a P300 in a test subject could be a re-

\footnotetext{
${ }^{9}$ The phrase "social epistemic systemic" is derived from Koppl. R. (2006)

${ }^{10}$ Meegan (2008) and Verscheure et al (2011) discuss other variants.

${ }^{11}$ Rosenfeld, P.J. (2011) and Meegan (2008)

${ }^{12}$ Polich, J. (2007)
} 
liable indicator of their recognition of certain information. If that information is taken, for example, from a crime scene, then the results of the P300 MDT might help to link a suspect to a crime scene, in a manner somewhat analogous to the use of DNA-matching. This would make the test forensically useful. ${ }^{13}$

It is no surprise then to learn there are those who advocate its forensic use. Perhaps the most conspicuous advocate is Lawrence Farwell, one of the original pioneers of the P300 MDT, ${ }^{14}$ who developed his own patented version of the test (sometimes referred to as "brain fingerprinting") ${ }^{15}$ and received some reasonably high-profile media exposure for his efforts to get it accepted by the courts. Those efforts were successful in one case, with a court ${ }^{16}$ admitting the evidence under the so-called Daubert test (discussed below), though the technique proved less successful in a later case. ${ }^{17}$ In subsequent years, Farwell has involved himself in classified military and security service tests of his technique, ${ }^{18}$ before recently reemerging to the public eye to argue for the strengths of his version of the P300 MDT.

There are, of course, critics of Farwell's test. ${ }^{19}$ One criticism of the test concerns the forensic uses to which it has been put. In the Harrington decision, in which the results of a P300 MDT were admitted to court, the test was used to exculpate a prisoner who had served 24 years in jail. The results of the test supposedly showed that certain information relevant to a crime was not present in the defendant's brain, but that information relevant to his alibi was. Now, it is somewhat doubtful that this had a significant effect on the decision of the court since a key witness in the earlier case had also recanted his testimony, but in any event, as Rosenfeld points out, ${ }^{20}$ the forensic value of Farwell's test result in this context was practically nil. Memories are constantly distorted, reconstructed and rewritten

${ }^{13}$ It should be noted that, as with DNA-matching, the fact that an accused person can be linked to a crime scene does not equate with their guilt, obviously additional steps are needed for that.

${ }^{14}$ Farwell, L. and Donchin, E. (1991)

15 For general details, see Farwell's company webpage, formerly located at www.brainwavescience.com, but now at www.governmentworks.com/bws. The unique feature of Farwell's test is that in addition to recording the P300 response it also focuses on something Farwell calls the MERMER response. Having been rather inactive in the academic community for a number of years (apparently due to military testing of his technique), Farwell has recently returned to publishing, with a number of research and review articles touting the strengths and weaknesses of his techniques. Farwell, L, Richardson, D, and Richardson, G. (2012); and Farwell, L. (2012)

${ }^{16}$ Harrington v. State of Iowa 659 N.W.2d 509 (Iowa 2003)

${ }^{17}$ Slaughter v. State of Oklahoma 105 P.3d 832 (Oklahoma 2005)

${ }^{18}$ Farwell, Richardson and Richardson (2012).

${ }^{19}$ Rosenfeld, J. P (2005) and Meegan (2008)

${ }^{20}$ Rosenfeld (2005) 
over the course of time. A person who was actually present at a crime scene 20 years ago may have forgotten certain details that the P300 MDT tries to test them on, thus resulting in a negative test that is not truly exculpatory. Similarly, a person who has rehearsed their alibi story for over 20 years could well recognise information connected with that story, despite it not being true. ${ }^{21}$ There are also a number of ethical concerns associated with the technology. Most obviously, misapplication of an epistemically faulty or unreliable test will degrade the quality of legal decision-making, which is itself ethically undesirable. In addition to this, concerns have been expressed about the effects of such techniques on cognitive liberty and autonomy. ${ }^{22}$ Nevertheless, there remains considerable enthusiasm about the forensic uses of MDTs $^{23}$ and even the critics of Farwell's test have proposed alternative, and they believe more reliable, versions of the P300 MDT. ${ }^{24}$ This wave of enthusiasm shows no signs of abating. ${ }^{25}$

At this juncture, and since it will become relevant later, it is worth briefly considering the differences between the P300 MDT and another type of test that has received considerable attention and (some) enthusiastic support in recent years, namely: fMRI lie detection. ${ }^{26}$ Like the P300 MDT, fMRI lie detection tests have received at least one day in court, ${ }^{27}$ though, as with the classic polygraph test, they failed to find a sympathetic audience. Still, as with the P300 MDT, there are those promote their forensic use ${ }^{28}$ and those who are deeply concerned. ${ }^{29}$

So what are the differences between the two tests? Well, there are many, but two are important for present purposes. First, like the classic lie detector test,

${ }^{21}$ Allen, J.J.B. \& Mertens, R. (2009)

${ }^{22}$ Sententia, Wyre (2004); Sententia, Wyre (2001); and Halliburton, C. (2007)

${ }^{23}$ See Verscheure et al (2011) for some notably enthusiastic discussions of such tests. One contributor (Patrick) argues that MDTs are an "idea whose time has come", p. 9, and another (Iacono) makes the case for its widespread use by law enforcement, pp 12-27.

${ }^{24}$ Rosenfeld is developing a version of the P300 MDT that makes use of something he calls the complex trial protocol. This, along with certain other testing techniques, makes the test more accurate and less prone to countermeasures. This is something I discuss in more detail in section 4. A list of his most recent publications can be found at:

http://groups.psych.northwestern.edu/rosenfeld/publications.html

${ }^{25}$ Farwell and Rosenfeld are the most prominent examples of this, with Farwell publishing six articles on his technique since 2011, and Rosenfeld publishing five in 2012 alone. See both authors webpages for copies of the relevant papers.

${ }^{26}$ Schauer (2012) contains an overview of the debate about fMRI lie detection. I discuss fMRI lie detection in more depth in Danaher J. (2011b) and (2011a)

${ }^{27}$ United States v Semrau, No. 07-10074 M1/P (W.D. Tenn. May 31, 2010).

${ }^{28}$ Most notably two companies Cephos Corp (www.cephoscorp.com) and NoLie MRI (www.noliemri.com)

${ }^{29}$ Greely, H. T. and Illes, J. (2007) 
fMRI techniques usually ${ }^{30}$ rely on a testing format - the control question test of dubious reliability. Since the goal of a lie detection test is to determine whether a suspect is lying or not, the emotional saliency of the test questions is an important feature of the test. But emotional saliency is difficult to control and is something that can be manipulated by the tester and altered by the context of the test. This has been thought to undermine the reliability of the test. ${ }^{31}$ The P300 MDT seems to avoid these problems because the goal of the test is not to determine deception, but to determine whether certain information is recognised. It is thought to be easier to create proper "control" questions in this format, ${ }^{32}$ which improves the reliability of the technique. Allied to this is the second main difference between the tests, which has to do with the nature of the error rates associated with them. While figures vary between experimental tests, Schauer suggests, from a review of the evidence, that the accuracy of fMRI lie detection ranges between 70$90 \%$. Noticeably, however, the number of false positive errors in fMRI tests can be quite high, ranging upwards of $20 \%$ in some cases. This presents a significant contrast with the P300 MDT. Although error rates for that test vary considerably too - with several tests reporting accuracy of near $100 \%{ }^{33}$ but others offering much lower accuracy rates (as low as $27 \%$ ) in more realistic mock-crime tests or when the risk of false memories is high ${ }^{34}$ - they are heavily skewed toward the false negative type of error. In other words, the test frequently says that information which should have been recognised by a test subject was not, or reaches an inconclusive outcome. At the same time, whenever it does say that information was recognised, it is pretty good indicator that this was indeed the case. This means that the test could have high probative value, higher than fMRI lie detection, provided it is used correctly. This is a point to which I shall return below.

In sum, the P300 MDT is an emerging forensic technique with a great deal of potential, but also with significant attendant risks. It is importantly different from a similar emerging technology, fMRI lie detection, in terms of its test format and its accuracy rates. Given its potential and its risks, it forms an interesting case study in the responsible use of emerging technologies.

${ }^{30}$ Note: since fMRI is simply an imaging-technique, it could potentially be used as the basis for a MDT. This is discussed in Gamer (2011). Nevertheless, this has not been developed to a significant extent yet. The P300 EEG-based technique has been much more fully developed.

${ }^{31}$ See Furedy, J. (1996) and (1988); and Ganis, G. and Rosenfeld, J.P. (2011)

${ }^{32}$ Verscheure et al (2011) on the advantages of the MDT. Note that deception may indirectly feature as part of the test. Rosenfeld, J.P. (2012

${ }^{33}$ Farwell, Richardson and Richardson (2012) and Iacono in Verscheure et al (2011) (focusing on MDTs more generally)

${ }^{34}$ Allen and Mertens (2009); and Mertens and Allen (2008) 


\section{The Law and Innovative Forensic Technolo- gies}

With a basic understanding of the P300 MDT in place, we can now consider exactly how the legal system should approach a novel forensic technology of this sort. In doing so a key theme emerges: there is a connection between the responsible use of innovative technologies of this sort, and the responsible innovation of an epistemic system such as the legal trial. In the attempt to develop and analyse that theme, this section performs two key functions. First, it explains what it means to call the legal trial an "epistemic system" and highlights the role of forensic technologies such as the P300 MDT in that system. Second, it identifies some tensions between legal and scientific standards for evidential success which may affect how and when such forensic technologies are used. This paves the way for the development of a novel framework in section 4 .

\subsection{The trial as an epistemic system}

Following Koppl, ${ }^{35}$ an epistemic system is here defined as any social system that (at least sometimes) generates judgments of truth or falsity. Typically, such systems involve interactions between two or more strategic agents, i.e. agents who must compete or cooperate with one another in order to secure their preferred outcomes. Koppl identifies two broad classes of such agents, senders and receivers, the former send information through the system, the latter interpret that information and issue a judgment of truth or falsity. The roles can overlap in one particular individual. When dressed in more formal garb, and when taking advantage of some ideas from game and information theory, Koppl's seemingly simple senderreceiver model can be transformed into a powerful tool for the analysis and design of social epistemic systems.

Such formalisms are not necessary for understanding the argument in this paper. All that matters here is that the legal trial can be understood as a social system that both generates judgments of truth and falsity, and that involves interactions between strategic agents. ${ }^{36}$ This is easily illustrated by reference to the classic model of legal decision-making, which although it is certainly incomplete, and doesn't do justice to the complexities of human reasoning, still has its essence captured by the following syllogistic pattern:

(1) If S did X, then legal consequence $\mathrm{Y}$ follows (legal rule)

(2) S did X (factum probandum)

\footnotetext{
${ }^{35}$ Koppl (2006)

${ }^{36}$ Danaher, J. (2011a)
} 
(3) Therefore, legal consequence $Y$ follows (verdict/ruling).

To be sure, legal cases can often be more complex than this, with many chains of syllogisms linked together in one trial, but the basic pattern of reasoning remains the same. It is this pattern, particularly the second premise in this pattern, that highlights the epistemic dimension of the trial. For it is this premise that states the factum probandum - the key legal fact that needs to be proved in each case - and the proof of that premise will be determined by strategic interactions between different legal agents.

We can see this by considering the dynamics of the trial in more depth. In order to prove the factum probandum, the court relies on evidence. This evidence is usually presented to the court in the form of testimony. In other words, witnesses are put before the court and asked to tell the court what they saw or what they experienced or, exceptionally in the case of experts, to offer opinions about what might have happened. The problem is that, at least in common law jurisdictions, the system is adversarial. Both sides want to prove different things, they present different witnesses to help them do so, and these witnesses oftentimes contradict one another. Thus, it becomes difficult for the court to figure out where the truth really lies, which in turn makes it difficult for it to perform its epistemic function in a fair and reliable manner.

Interestingly, it is this very property of the trial that highlights the allure of forensic technologies like the P300 MDT or the fMRI lie detector. When witnesses are incentivised to either mislead or, at a minimum, not to assist the court in the fulfillment of its epistemic function - as they are given the strategic dynamics of the adversarial trial - we have the problem of false or absent testimony. To overcome this problem, courts can adopt two strategies: (a) incentivise the presentation of truthful testimony (which they do through the use of subpoenas, perjury laws and the like) or (b) use some forensic technology to bypass or correct for false or absent testimony. MDTs and lie detector tests are examples of strategy (b). An MDT can allow a court to link a suspect to a crime scene, irrespective of their actual testimony, by checking to see whether their brains respond to crime-relevant information. Similarly, a lie detector test could allow the court to infer general deceptiveness on the part of a witness, ${ }^{37}$ which would enable them to make judgments about the reliability of their testimony. Of course, this can only happen if the tests are valid and reliable, but assuming they are the benefits could be significant.

It is important to bear in mind, however, that even though judgments of truth or falsity play an important role in the trial, and improving the accuracy of those judgments is a major policy concern, the epistemic dimension of the trial is complemented by a number of normative and ethical dimensions. The trial is not sim-

${ }^{37}$ Though, problematically this is all they seem capable of doing. See Danaher (2011b) 
ply an instrument for reaching judgments about the truth or falsity of particular claims; it is a procedure that protects and respects the central moral qualities of the people who operate within it. Thus, there are procedural norms associated with the standards of proof, the right to a fair trial, and the protection of vulnerable witnesses. These norms play a significant part in determining whether it is appropriate to make use of novel forensic technologies like the P300 MDT, as we shall see.

To summarise, the legal trial is an epistemic system, i.e. a social system that is (at least partly) concerned with generating judgments of truth or falsity. The ability of this system to generate more accurate judgments of truth or falsity could be greatly assisted by the use of novel forensic technologies such as the P300 MDT, but when assessing whether and when it is appropriate to do this, we need to bear in mind the ethical/normative dimension of the system too.

\subsection{Problems with existing admissibility tests}

The next question is whether existing protocols and tests for deciding on the use novel forensic technologies are fit for purpose? In other words, do they allow for the effective use of such technologies in a manner that is sensitive to the epistemic and ethical/normative dimensions of the trial? The claim I wish to defend is that they are not, and in doing so I clarify and build upon some arguments made by Frederick Schauer in relation to the use of fMRI lie detection. ${ }^{38}$ Schauer's concern is not to directly challenge existing protocols and tests - though he does gesture in that direction ${ }^{39}$ - but rather to highlight important tensions between scientific and legal norms of evidential value. These tensions represent faultlines between the scientific and legal epistemic systems that will need to be addressed by any proposed framework.

Schauer notes that, from its earliest days, the lie detector test it has struggled to win acceptance in the courts. This trend has continued despite the advent of newer versions of the test using fMRI imaging techniques. This is also true of the P300 MDT which, despite some initial success, is generally treated with a good deal of trepidation by both researchers, lawyers and courts. ${ }^{40}$ Schauer questions the tenability of this trend by defending one overarching claim, which we may call "Schauer's Thesis":

Schauer's Thesis: Whether fMRI lie detection (or P300 MDT) evidence should be admitted to court is not simply a question of its scientific validity and reliability, it also (perhaps primarily) a question of the normative and

\footnotetext{
${ }^{38}$ Schauer (2012) and (2010)

39 Schauer (2010) from p. 1214 onwards, where he offers some critique of Daubert.

${ }^{40}$ Rosenfeld in Verscheure et al (2011); and Meegan (2008)
} 
ethical function of the law. That is to say, questions of evidential utility are fundamentally determined by legal-ethical standards, not purely scientific ones.

This claim is significant in that current tests for the admissibility of scientific evidence, such as DNA fingerprinting and other forensic techniques, rely heavily on, though are not isomorphic with, scientific standards of validity and reliability. For instance the Daubert test, which is now advocated for introduction in the $\mathrm{UK},{ }^{41}$ states that judges should assess scientific evidence by referring to the indicia of reliability that are common in the scientific world. These indicia include things like "known error rates", "general acceptance within the relevant scientific community", "testability" and "passing peer review". The problem is that this approach can yield significant legal territory to the norms of scientific inquiry, and while this may often be appropriate, Schauer's Thesis suggests that these territories may have very different topographies. What scientists rightfully deem "good evidence" and what legal theorists rightfully deem "good evidence" may be two different things. It is important not to lose sight of this.

Schauer supports his thesis with two arguments, which we shall call the "probative context" and the "epistemic progress" arguments. Let's look first at the probative context argument. The key premise of this argument is that the value of any evidence placed before a court depends largely on three factors:

Probability: Does the evidence raise or lower the probability of the factum probandum and if so, by how much does it raise or lower its probability?

Standard of Proof: What confidence threshold must the probability of the factum probandum cross in order for it to count as being proved or not proved?

Legal Purpose: Is the evidence being submitted in order to prove or disprove the factum probandum?

The probative context varies depending on the legal issue at stake, and the party on whose behalf the evidence is proffered. For example, in criminal cases, the standard of proof for the prosecution is beyond a reasonable doubt. This is a notoriously fuzzy standard, but suppose that it corresponds to a $95 \%(0.95)$ probability of the factum probandum being true. In that case, in order to secure a conviction, the prosecution would need to introduce a body of evidence that (in its totality) raises the probability of the factum probandum to the $95 \%$ threshold. Contrariwise, the defence would succeed if they could introduce evidence that prevented the probability from crossing that $95 \%$ threshold. Thus, the probative

\footnotetext{
${ }^{41}$ Law Commission (2011)
} 
value of the evidence varies depending on who is presenting it, which is another of the variables of the probative context.

This is important because it feeds into the assessment of the value of lie detection or MDT evidence. Schauer notes that fMRI lie detector tests have reported accuracy rates that vary from $70-90 \% .^{42}$ This might seem scientifically unimpressive, but they are better than chance at identifying deceptive individuals, and in the right context this could be probatively valuable. For example, in a criminal trial, although a $70 \%$ accuracy rate might not suffice to prove that someone is guilty, it might suffice to prove reasonable doubt. So, for instance, if I am 70\% likely to be telling the truth about my alibi when I am being charged for murder, then (Bayesian considerations to one side) it might be highly useful for the court to be made aware of this fact. Breaking it down, the argument Schauer is making looks something like this:

(4) In its present form(s), the accuracy rate of fMRI lie detection is somewhere between $70 \%$ and $90 \%$.

(5) In some probative contexts, a $70 \%$ likelihood that $\mathrm{X}$ is telling the truth/lying is highly probative.

(6) Therefore, fMRI lie detection could be useful (even in its present form) in some probative contexts.

Thus we have the probative context argument. It should be pointed at that premise (2) can be defended with a number of examples. The criminal example is used here because it is possibly the most straightforward, but in civil trials the standard of proof is much lower (balance of probabilities) and hence the lie detector test could be highly probative in those contexts too, despite seemingly low accuracy rates. The same argument could be co-opted into the defence of the forensic use of the P300 MDT. The tendency of that test to yield fewer false positives and more false negatives. A test with those features could be highly useful in some contexts. There is no need to dwell on the technicalities here though. The important point is that decisions about the utility of evidence need to be highly sensitive to the probative context in which that evidence is presented, which is something they cannot be if they are overly-beholden to scientific standards of epistemic success since the probative context of science is quite different.

Another problem with existing approaches to determining whether novel forensic technologies should be used is the problem of status quo bias ${ }^{43}$ Schauer illustrates this with the epistemic progress argument.

\footnotetext{
${ }^{42}$ Schauer (2012)

${ }^{43}$ A general problem in applied ethical reasoning. See Bostrom, N. and Ord, T.
} (2006) 
An epistemic system can be said to under progress whenever there is some overall improvement in its epistemic efficiency. "Efficiency" is defined as a measure of the likelihood of the system reaching a true judgment. ${ }^{44}$ The basic idea is that epistemic progress is a good thing, and that any reform to the system that allows it to progress would be welcome provided it does not compromise the ethical/normative aspects of the system (a point to which I shall return). Epistemic progress is always assessed relative to the existing level of epistemic efficiency. Thus, if we wished to argue in favour of a particular reform, we would have to do so by directly referencing the current level of efficiency. This relativistic aspect of epistemic progress has one interesting effect: if the current level of epistemic efficiency is low, then a proposed reform to that system, even one with an unimpressive level of overall accuracy, may nevertheless be warranted on the grounds that it still raises the efficiency of the system.

Schauer argues that this could be true in the case of fMRI lie detection. He does so by highlighting how existing solutions to the false or absent testimony problem are lacking. For example, historically, the administration of the religious oath was thought to incentivise truth-telling. In a culture in thrall to the fear of God and hell, this may have held some sway, but in its modern secular form the oath relies on the desire to be honest and the threat of perjury to do its work. Arguably, neither of these are particularly effective and certainly have no known accuracy rates. So with just the oath to protect us from false testimony, the epistemic efficiency of the trial is unclear. Similarly, robust cross examination, though often lauded, is unlikely to be effective at resolving the problem. As Schauer notes, cross examination may expose inconsistencies in certain cases, but is unlikely to do so in the case of the seasoned or practiced liar (movie depictions notwithstanding). In these cases we may be left with contradictory testimonies, which can be very difficult for a jury to assess. Furthermore, as with the oath, there are no known accuracy rates associated with cross-examination. In light of these comparators, the admission of fMRI lie detection would seem to represent epistemic progress. Since it does have known accuracy rates, and since it can do something to break the deadlock between contradictory testimonies, it could lead to epistemic progress. Again, something similar could be true in the case of the P300 MDT, although that technique might have a greater impact on the problem of absent testimony.

Schauer's two arguments help to readjust our perspective on the relationship between the legal trial and novel forensic technologies such as the P300 MDT. But they are not entirely satisfactory. For one thing, it is possible to dispute some of his factual claims about fMRI lie detection. ${ }^{45}$ For another, it is not clear whether they mount a serious challenge to existing protocols or tests for determining the utility of novel forensic techniques. Is a new framework really needed to address Schauer's concerns?

${ }^{44}$ The term and its definition are taken from Koppl (2006)

${ }^{45}$ Schauer (2012) deals with some such criticisms. 
If we assume that the current framework is represented by some version of the Daubert test, then it is possible to argue that there isn't really a problem. A Daubert-style test, as mentioned earlier, requires judges to assess the merits of scientific evidence by reference to a number of commonly-recognised indicia of reliability: error rates, peer review, sound methodology and so on. And while these are scientific indicia, there is no reason why an attentive mind could not apply those standards in a manner that is consistent with the epistemic and normative aims of the legal system. Thus, for example, a judge could look to the known error rate of a forensic technique that falls below what might be desirable for scientific purposes, but can still accept it if the probative context of the law would benefit from it. There is nothing in a Daubert-style test that prevents him or her from doing so. The test does not subordinate the law to science.

On a purely formal level, then, a Daubert-style test is neutral with respect to the types of concerns raised by Schauer: it doesn't actively seek to address them, nor does it actively exacerbate them. It is a small part of the overall apparatus the law uses to determine which kinds of evidence are worth considering and which are not. But this formal neutrality is itself problematic. By not actively directing our attention to Schauer's concerns, it is too easy for the person adopting the test to lose sight of epistemic progress and probative context. Arguably this is what Schauer shows to have happened in relation to polygraph and fMRI lie detector tests. This is compounded by the fact that, in terms of historical impetus, Daubert was created to address the problem of "junk" science, i.e. to close the doors of the court to bad forensic evidence. As Schauer himself points out, this historical background tends to support the status quo within the legal system, which may actually be improved by "bad" forensic techniques. ${ }^{46}$

One might suppose that simple emendations to the Daubert-test could solve the problem. By adding additional criteria to the test, we could overcome its neutrality and encourage active engagement with epistemic progress and probative context. Perhaps we could, but this would be a partial solution at best. This modified Daubert would still only look to the epistemic dimension of the trial and how some of the particular norms of the legal system play an important role in determining the probative value of evidence. This leaves other normative considerations in the lurch, either to be ignored or to be dealt with by other evidentiary rules. For example, Schauer himself explicitly considers the role of the rule against "unfair prejudice" in determining the admissibility of fMRI lie detection evidence. ${ }^{47}$ According to this rule, otherwise epistemically reliable evidence is to be excluded from the trial if juries are likely to give it undue weight in their deliberations. As he points out, preliminary research has revealed that people are more persuaded by neuroscience-based evidence than they should be, which suggests it might have an unfairly prejudicial effect. ${ }^{48}$ Whether this is true need not concern

\footnotetext{
${ }^{46}$ Schauer (2010), pp. 1216-17

${ }^{47}$ Schauer (2012) and Goldberg, D. (2008)

${ }^{48}$ Klaming, L. (2011) is somewhat more tentative on this point than Schauer.
} 
us now, what is significant is how Schauer considers this issue after making his two general arguments in favour of his core thesis (about the role of legal and evaluative considerations in determining the admissibility of evidence), treating it as an additional point, not something that is intimately bound-up with the normative concerns motivating the earlier arguments. This represents a general problem with evidence law: there are many rules governing the exclusion of certain types of evidence, each of which affects how the trial system develops, but which are lacking some underlying unifying theory ${ }^{49}$ about the normative function of the trial.

This should not be the case. A theoretical framework that provided a grounding for Schauer's arguments could be used to assess forensic techniques, and also to assess other normative and procedural aspects of the legal trial. It would not only give us a roadmap for the responsible use of novel technologies like the P300 MDT, but a roadmap for the responsible innovation of an epistemic system like the legal trial. The job of the next section is to provide that theoretical framework.

\section{The Legitimacy Enhancing Test}

The proposed framework is grounded in the notion of legitimacy. Put most simply, it requires a court (or other agency) when tasked with considering reforms to the trial - where "reforms" is taken to include decisions as to evidential admissibility - to ask whether that reform would enhance the legitimacy of the trial. The result is the legitimacy enhancing test (LET). This deceptively simply test allows the court to draw upon a rich theoretical literature about the nature of legitimacy conditions, which in turn bring together the disparate normative considerations highlighted in the preceding section. The remainder of this section will defend this test. It does so in two parts. First, it sets out the basic elements of the test, simplifying it to an argument with two premises: a normative premise and a factual premise. It then discusses each premise in sequence, noting how they supply the theoretical depth and unity absent from Schauer's analysis. The arguments here are programmatic, intending to provide stimulus for future debate and research, not a comprehensive defence of the test. Areas in which the theoretical basis of the test needs further elaboration will be highlighted, though in doing so I try to indicate how I think that elaboration could work.

\subsection{The test itself}

A central concept - perhaps the central concept - in contemporary political theory is that of legitimacy. ${ }^{50}$ The concept addresses the basic challenge of politi-

\footnotetext{
${ }^{49}$ Laudan, L (2011)

${ }^{50}$ Peter, F. (2008) and (2007)
} 
cal authority, namely that the exercise of authority tends to be coercive and autonomy-undermining. That is to say: whenever the government exerts its authority, the result is typically that somebody, somewhere, is forced to do something they would otherwise have preferred not to do. Prima facie, this is unjustifiable. The notion of legitimacy is what rescues political authority from this prima facie unjustifiability because a coercive rule or practice becomes justifiable if it satisfies a set of legitimacy conditions.

The LET takes advantage of this concept in formulating a test for determining whether novel forensic technologies should be used in the legal trial. What's more it does so in a way that is sensitive to the probative context, the relativistic nature of epistemic progress, and the other normative dimensions of the trial. To see this, we can start by sketching the structure of the test, which can be reduced to a simple syllogistic argument.

(7) If a change to an epistemic system with coercive powers (such as the legal trial) would enhance the legitimacy of that system, then that change is to be welcomed (normative premise)

(8) Change $X$ would/would not enhance the legitimacy of the trial (factual premise).

(9) Therefore, change $\mathrm{X}$ is/is not to be welcomed.

The word "change" is used in the broadest possible sense. An epistemic system such as the trial could be changed by a number of things, with the use of novel forensic technologies being but one example of a change. It is this broadness that allows the LET to not only provide guidance about the responsible use of a novel forensic technology, but also to provide guidance for the responsible innovation of the epistemic system as a whole.

In practical terms, the LET works like this: whenever a court (or other agent within an epistemic system) must consider a change to that system, they simply ask themselves whether the above argument is true, or probably true, in the case of the proposed change. By focusing on legitimacy enhancement the LET will direct their attention to the need for epistemic progress relative to the status quo, and by focusing on legitimacy it will direct their attention to the epistemic and normative concerns mentioned in the preceding section. In doing so, the normative premise supplies the theoretical background missing from Schauer's analysis and the modified Daubert test: it grounds, unifies and expands our assessment in a way that those proposals do not. Let's unpack this in a little more detail. 


\subsection{The premises in practice}

Although the truth of the normative premise need not be considered in practice - it can be taken as a background normative presupposition - some defence of it is in order here. In brief: legitimacy conditions must be met in order for a coercive act of political authority to be justified. The rationale for this is grounded in a liberal model of the state, according to which the default moral position in society is one of non-intervention in individual autonomy. Deviations from the default position need to be justified to the citizenry..$^{51}$ Legitimacy conditions are what determine whether this can be done. Hence, the method of justification is through the satisfaction of legitimacy conditions. Since the trial plays an important role in the exercise of coercive political authority, ${ }^{52}$ it follows that it needs to be justified in light of legitimacy conditions. ${ }^{53}$ This is why the normative premise is appropriate in this context. Interestingly, this highlights a limitation of the LET: it only applies to epistemic systems with some coercive power. If the system has no coercive power, then the legitimacy test is inappropriate. However, that limitation is not particularly severe since a good number of social epistemic systems have coercive power and it is oftentimes the fact that they deliver judgments of truth or falsity that grants them this power.

The strengths of the normative premise lie in how the concept of legitimacy gets fleshed out. There is a rich philosophical debate about which conditions supply the legitimacy needed for political justification. This debate has generated two distinct schools of thought: proceduralism and instrumentalism. ${ }^{54}$ According to proceduralism, what legitimates a coercive decision are the features of the procedure through which that decision was made; according to instrumentalism, what legitimates a coercive decision are the outputs of the procedure, specifically whether those outputs reach or get close to the right conclusion, normatively and/or epistemically speaking. Applying this to the trial, proceduralism would be concerned with the propriety of the trial procedure itself, i.e. whether it provides a forum in which the accused can be heard, whether it is biased and unfairly prejudicial, whether it respects individual autonomy, privacy and so on. On the other hand, instrumentalism would be concerned with whether the trial reaches the right verdict. This would be the case, in part at least, if the correct verdict about the factum probandum is reached.

The goal here is not to privilege one particular theory of legitimacy over another. Quite the opposite in fact. I suspect all the major theories highlight proper-

${ }^{51}$ Gaus, G. (2003); and (2010)

${ }^{52}$ I discuss this at great length in Danaher, J. (2013)

${ }^{53} \mathrm{This}$ is not to say that the normative function of the trial reduces to that of legitimacy, merely that legitimacy is an important part of the normative justification of the trial, whatever its normative function may be.

${ }^{54}$ On proceduralism: Machin, D. (2009); Estlund, D. (1993) and (2003); Peter, F. (2008). On instrumentalism: List and Goodin (2001); and Marti, J.L (2005) 
ties that normatively ideal epistemic systems exemplify and the goal is to bring all of those properties into consideration under the common umbrella of "legitimacy conditions". Thus, I propose that in using the LET we adopt a "mixed" account of legitimacy. In doing so, we provide a unifying framework for assessing the concerns in section 3. Specifically, by paying attention to both the procedural and instrumental dimensions of legitimacy, and to the "enhancing" potential of any proposed reform, we can do justice to Schauer's probative context and epistemic progress arguments, as well as the other normative requirements of the trial such as respect for autonomy, privacy and moral equality. This can be done by asking the following three, deceptively simple, questions:

A. Does the proposed change enhance the non-strategic epistemic efficiency of the trial?

B. Does the proposed change enhance the strategic epistemic efficiency of the trial?

C. Does the proposed change enhance the procedural virtues of the trial?

The first two questions deal with the instrumental side of legitimacy, focusing as they do on whether the change helps the system reach the right verdict about the factum probandum. The third question deals with the procedural side of legitimacy, focusing on whether the proposed change respects the rights of the people operating within the system. If one can answer "yes" to each question, then the change is acceptable. If the answers vary, then some careful balancing of the procedural and instrumental advantages will need to be considered.

On this point, it is important to bear in mind that the LET proposes a multidimensional test for epistemic reform. Broadly speaking, the instrumentalist and proceduralist concerns represent the two major dimensions to the test, but these (in particular the proceduralist dimension) can probably be broken down into a number of separate concerns. This raises the spectre of relativism and pluralism in the application of the test. It is possible that the many different kinds of legitimacy condition covered by the test are not reducible to one another, and therefore that reforms which satisfy different sets of those conditions cannot really be assessed relative to one another. For instance, maybe a reform which scores highly in terms of epistemic efficiency cannot be compared to a reform that scores highly in terms of its respect for privacy. This is indeed a serious concern and I can only gesture at a response to it here. The response would be that the plurality and irreducibility of legitimacy conditions does not entail their incommensurability, nor their incomparability. ${ }^{55}$ As other have pointed out, ${ }^{56}$ it is possible to rank plural values relative to one another. If that's right then it is also possible to rank different proposed re-

\footnotetext{
${ }^{55}$ See Chang (2013) and forthcoming; and Gaus (2003) on this point.
}

${ }^{56}$ Chang (2013) and Gaus (2003). 
forms, relative to the status quo and to one another, even if those proposed reforms exemplify different sets of legitimacy condition. Admittedly, however, this is something that would require further specification if the LET is to become fully persuasive.

Finally, one potentially confusing aspect of this test is the reference to "strategic" epistemic efficiency in the second question. What differentiates this from non-strategic epistemic efficiency? The idea is that since epistemic systems involve interactions between strategic agents, we can never consider the epistemic virtues of a proposed change without also considering the effect of that change on the incentives of those agents. I consider an illustration of this problem below.

To summarise, the LET provides a simple, unifying framework for determining the responsible use of innovative forensic technologies, and the responsible innovation of the legal trial as a whole. It incorporates the concerns developed by Schauer in his analysis of fMRI-based lie detection, but supplies a deeper theoretical underpinning for those concerns (viz. the concept of legitimacy) which can in turn incorporate a broader, pluralistic set of concerns (procedural and instrumental).

\section{Conclusion}

I conclude by simply applying the LET to the case of the P300 MDT. I do so by asking and answering the three questions posed above. The application is not exhaustive, and should not be considered to definitively determine whether or not the P300 MDT should be used. Rather, it provides an illustration of how the framework defended in this article can be used in practice.

First, would the use of the P300 MDT enhance the non-strategic epistemic efficiency of the trial? The answer to this is "it depends" the probative context since that determines the epistemic goals of the trial and the measure of efficiency. The clear strength of the technique is that it addresses the false or absent testimony problem, it does so in a manner that is better than chance, ${ }^{57}$ and it could be particularly effective when other methods of addressing the testimony problem (e.g. fingerprint or DNA evidence) are themselves absent. Furthermore, it addresses these problems in a manner that enhances epistemic efficiency relative to the status quo. This positive assessment must be tempered by some concerns about the ability of the test to distinguish true from false memories, and to detect recognition long after the crime has occurred (tests suggest reliability up to one month afterwards). ${ }^{58}$ Protocols that determine when it is not safe to use the test could, however, correct for these problems. ${ }^{59}$

${ }^{57}$ See references cited in ns 18-21, all suggest that it is better than chance. Also, Meegan (2008) and Verscheure et al. (2011)

${ }^{58} \mathrm{Hu}$ and Rosenfeld (2012)

${ }^{59} \mathrm{~J}$. Allen (2008) suggests a possible protocol relating to false memory. 
Second, would the use of the P300 MDT enhance the strategic epistemic efficiency of the trial? If use of the P300 MDT becomes common place in law enforcement, it might incentivise changes in behaviour that thwart the utility of the test. A classic illustration of this might be the fact that glove-wearing was incentivised following the advent of fingerprint matching. Classic lie detector tests exhibit this kind of strategic weakness because they are vulnerable to countermeasures. That is: test subjects can undermine the test by performing voluntary acts that reduce its accuracy. This problem has been studied by P300 researchers ${ }^{60}$ and it has been found that complex testing protocols or the subliminal presentation of signals to the test subject make it far less vulnerable to countermeasures. This suggests that strategic epistemic weakness may not be a problem for this technique.

Finally, would the use of the P300 MDT enhance the procedural virtues of the trial? A more appropriate question might be: would it reduce or undermine those virtues? The answer is far from clear. One major concern might be that the test is used in practice as an interrogation prop. That is: the threat of the test is something a police investigator uses to force a confession, with the confession then being the main piece of evidence used at trial, not the result of the test. This might be thought to undermine the accused's right to a fair trial. It is suggested that strict rules for the use of the test could help to overcome this problem, though oversight of its actual use will be important. Similarly, although many are concerned about the risk of unfair prejudice when it comes to brain-based forensic techniques, this is overstated: such risks are present with other kinds of evidence that are routinely used, ${ }^{61}$ and the risk could be minimised by parallel reforms to the jury system. ${ }^{62}$ The test may also raise privacy concerns ${ }^{63}$ depending on the nature of the evidence collected. But one suspects those are relatively minor since the test, at best, may be used to link a suspect to a particular piece of information. This would be analogous to the dangers to privacy from matching DNA or fingerprints from the crime scene and so the concerns would be no more serious than those raised by those techniques. Still, some caution must be expressed. It is possible that the test inadvertently uncovers other details about the suspect that have yet to be fully appreciated. For example, perhaps information from the EEG-scabs could be used to make inferences to cognitive or intellectual ability. Although I can find no reports of this, it is nevertheless something to be wary about in the future.

In sum, there might be case to be made in favour of the forensic use of the P300 MDT, but this case is best made within the framework supplied by the LET. This is because the LET creates a systematic and unifying framework for deter-

${ }^{60}$ Meixner, J. and Rosenfeld, J.P. (2010)

${ }^{61}$ Schauer (2012)

${ }^{62}$ Danaher, J. (2013)

${ }^{63}$ Vedder and Klaming (2010) discuss privacy problems in relation to another possible reform of the legal epistemic system: eyewitness enhancement; I respond to their arguments at length in Danaher, J. (2013) 
mining the responsible use of novel forensic technologies, and provides guidelines for the responsible innovation of social epistemic systems like the legal trial. Furthermore, the LET does this while remaining sensitive to the epistemic and procedural needs of the trial.

\section{Bibliography}

Adler, K. 2007. The Lie Detectors: The History of an American Obsession. New York: Free Press.

Allen, John .J.B. 2008. Not Devoid of Forensic Potential, But... 8(1): 27-28

Allen, John .J.B. \& R. Mertens. 2009 Limitations to the Detection of Deception: True and False recollections are Poorly Distinguished using an Event-related Potential Procedure. Social Neuroscience 4(6): 473-490.

Ben-Shakar, G. 2002. A Critical Review of the Control Questions Test. In Kleiner, M. (Ed) Handbook of Polygraph Testing. London: Academic Press.

Bostrom, Nick and Toby Ord. 2006. The Reversal Test: Eliminating Status Quo Bias in Applied Ethics. Ethics 116: 656-679

Chang, R. 2013. Incommensurability and Incomparability. In La Follette, H. (Ed) International Encyclopedia of Ethics. Oxford: Blackwell.

Chang, R. forthcoming. Value Pluralism. In Wright, J.D. (Ed) International Encyclopedia of the Social and Behavioral Sciences 2nd Edn. Elsevier. (Preprint available at: http://ruthchang.net/wpcontent/uploads/2012/11/VALUEPLURALISMsubmittedupdateforweb1.pdf accessed 29/5/13)

Danaher, John. 2010. Scientific Evidence and the Criminal Law: Lessons from Brain-based Lie Detection. Judicial Studies Institute Journal 10: 94

Danaher, John. 2011a. Blind Expertise and the Problem of Scientific Evidence. International Journal of Evidence and Proof 15(3) 207-231

Danaher, J. 2011b. The Future of Brain-based Lie Detection and the Admissibility of Scientific Evidence. Irish Criminal Law Journal 21: 67-76

Danaher, John. 2013. On the Need for Epistemic Enhancement: Democratic Legitimacy and the Enhancement Project. Law, Innovation and Technology 5(1): 85112. 
Estlund, David. 1993. Making Truth Safe for Democracy. In Copp, Hampton and Roemer (Eds) The Idea of Democracy. Cambridge: Cambridge University Press.

Estlund, David. 2003. Why not Epistocracy?. In Reshotko, N (Ed) Desire, Identity and Existence: Essays in Honour of T.M. Penner. Kelowna, B.C.: Academic Printing and Publishing.

Farwell, Lawrence. 2012. Brain fingerprinting: a comprehensive tutorial review of detection of concealed information with event-related brain potentials. Cognitive Neurodynamics 6: 115-154

Farwell, Lawrence. 2011. Brain Fingerprinting: Corrections to Rosenfeld. Scientific Review of Mental Health Practice 8: 56-68

Farwell, Lawrence and E. Donchin. 1991. The Truth will Out: Interrogative Polygraphy ("Lie Detection") with Event Related Potentials. Psychophysiology 28: 531-547

Farwell, Lawrence, D. Richardson and G. Richardson. 2012 Brain Fingerprinting Field Studies Comparing P300-MERMER and P300 brainwave responses in the detection of concealed information. Cognitive Neurodynamics DOI 10.1007/s11571-012-9230-0

Furedy, John. 1996. The North American Polygraph and Psychophysiology: Disinterested, Uninterested and Interested Perspectives. International Journal of Psychophysiology 21: 97

Furedy, John, and R. Heselgrave. 1988. The Validity of the Lie Detector: A Psychophysiological Perspective. Criminal Justice and Behavior 15: 219

Gamer, Matthias. 2011. Detecting of deception and concealed information using neuroimaging techniques. In Verscheure, B., Gershon Ben-Shakar and Ewout Meijer (Eds) Memory Detection: Theory and Application of the Concealed Information Test. Cambridge: Cambridge University Press.

Ganis, G. J.P. Rosenfeld, J.P. 2011. Neural Correlates of Deception. In Illes, J. and Sahakian, B. (eds) The Oxford Handbook of Neuroethics. Oxford: OUP.

Gaus, Gerald. 2003. Contemporary Theories of Liberalism. London: Sage Publications.

Gaus, Gerald. 2010. The Order of Public Reason. Cambridge: Cambridge University Press.

Goldberg, D. 2008. The Detection of Constructed Memories and the Risks of Un- 
due Prejudice. American Journal of Bioethics 8: 23-24

Greely, Hank T. and Illes, J. 2007. Neuroscience-based Lie Detection: The Urgent Need for Regulation. American Journal of Law and Medicine 377-431

Halliburton, C. 2007. Letting Katz out of the Bag: Cognitive Freedom and Fourth Amendment Fidelity. Hastings Law Journal 59: 309

$\mathrm{Hu}$, X. and J.P. Rosenfeld. 2012. Combining the P300-complex trial-based Concealed Information Test and the reaction time-based autobiographical Implicit Association Test in concealed memory detection. Psychophysiology 49: 1090

Iacono, W. G. 2008. Effective Policing: Understanding How Polygraph Tests Work and are Used. Criminal Justice and Behaviour 35: 1295

Klaming, Laura. 2011. Does Neuroscientific Evidence Bias Legal DecisionMaking? Some Preliminary Findings. Law, Innovation and Technology 3: 303-317

Koppl. Roger. 2006. Epistemic Systems. Episteme: a journal of social epistemology 2: $91-106$

Laudan, Larry. 2011. Truth, Error and Criminal Law. Cambridge: Cambridge University Press.

Law Commission. 2011. Expert Evidence in Criminal Proceedings in England and Wales (Law Com No. 325)

List, C. and Goodin, R. 2001. Epistemic Democracy: Generalizing the Condorcet Jury Theorem. Journal of Political Philosophy 9: 277

Machin, D. 2009. The Irrelevance of Democracy to the Public Justification of Political Authority. Res Publica 15: 103

Marti, J.L. 2005. The Epistemic Conception of Deliberative Democracy Defended. In Besson and Marti (Eds) Deliberative Democracy and its Discontents. London: Ashgate Publishing.

Meegan, D. 2008. Neuroimaging Techniques for Memory Detection. American Journal of Bioethics 8: 9-20

Meixner, J. and Rosenfeld, J.P. 2010. Countermeasure Mechanisms in a P300based Concealed Information Test. Psychophysiology 47: 57-65

Mertens, R. and Allen, JJB. 2008. The role of psychophysiology in forensic assessments: Deception detection, ERPs and virtual reality mock crime scenarios. Psychophysiology 45: 286-298 
National Academies of the Sciences Report. 2008. The Polygraph and Lie Detection. Washington, DC: National Academies Press.

Peter, Fabienne. 2007. Democratic Legitimacy and Proceduralist Social Epistemology. Politics, Philosophy and Economics 6(3): 329

Peter, Fabienne. 2008. Pure Epistemic Proceduralism. Episteme 5: 33-55

Peter, Fabienne. 2008. Democratic Legitimacy. London: Routledge.

Polich, J. 2007. Updating P300: An integrative theory of P3a and P3b. 118(10) Clinical Neurophysiology. 118(10): 2128-2148

Rosenfeld, J. 2005. Brain Fingerprinting: a Critical Analysis. Scientific Review of Mental Health Practice 4: 20-37

Rosenfeld, J. Peter. 2011. P300 in Detecting Concealed Information. In Verscheure, B., Gershon Ben-Shakar and Ewout Meijer (Eds) Memory Detection: Theory and Application of the Concealed Information Test. Cambridge: Cambridge University Press.

Schauer, Frederick. 2010. Can bad Science be Good Evidence: Neuroscience, Lie Detection and Beyond. Cornell Law Review 95: 1191

Schauer, Frederick. 2012. Lie Detection, Neuroscience, and the Law of Evidence. Virginia Public Law and Legal Theory Research Paper 2012-49

Sententia, Wyre. 2001. Brain Fingerprinting: Databodies to Databrains. Institute for Ethics and Emerging Technologies, available at http://ieet.org/index.php/IEET/print/1412

Sententia, Wyre. 2004. Cognitive Liberty and Converging Technologies for Improving Human Cognition. Annals of the New York Academy of Sciences, 1013: 221-228.

Vedder, A. and Klaming, L. 2010. Human Enhancement for the Common Good Using Neurotechnologies to Improve Eyewitness Memory. AJOB: Neuroethics 3(1): 22-33

Verscheure, Bruno, Gershon Ben-Shakar and Ewout Meijer (Eds). 2011. Memory Detection: Theory and Application of the Concealed Information Test. Cambridge: Cambridge University Press. 
